\title{
LAUNCHING INNOVATION IN SCHOOLS \\ IN REVIEW
}




\section{"Change is only meaningful if it affects the day-to-day lives of students."}
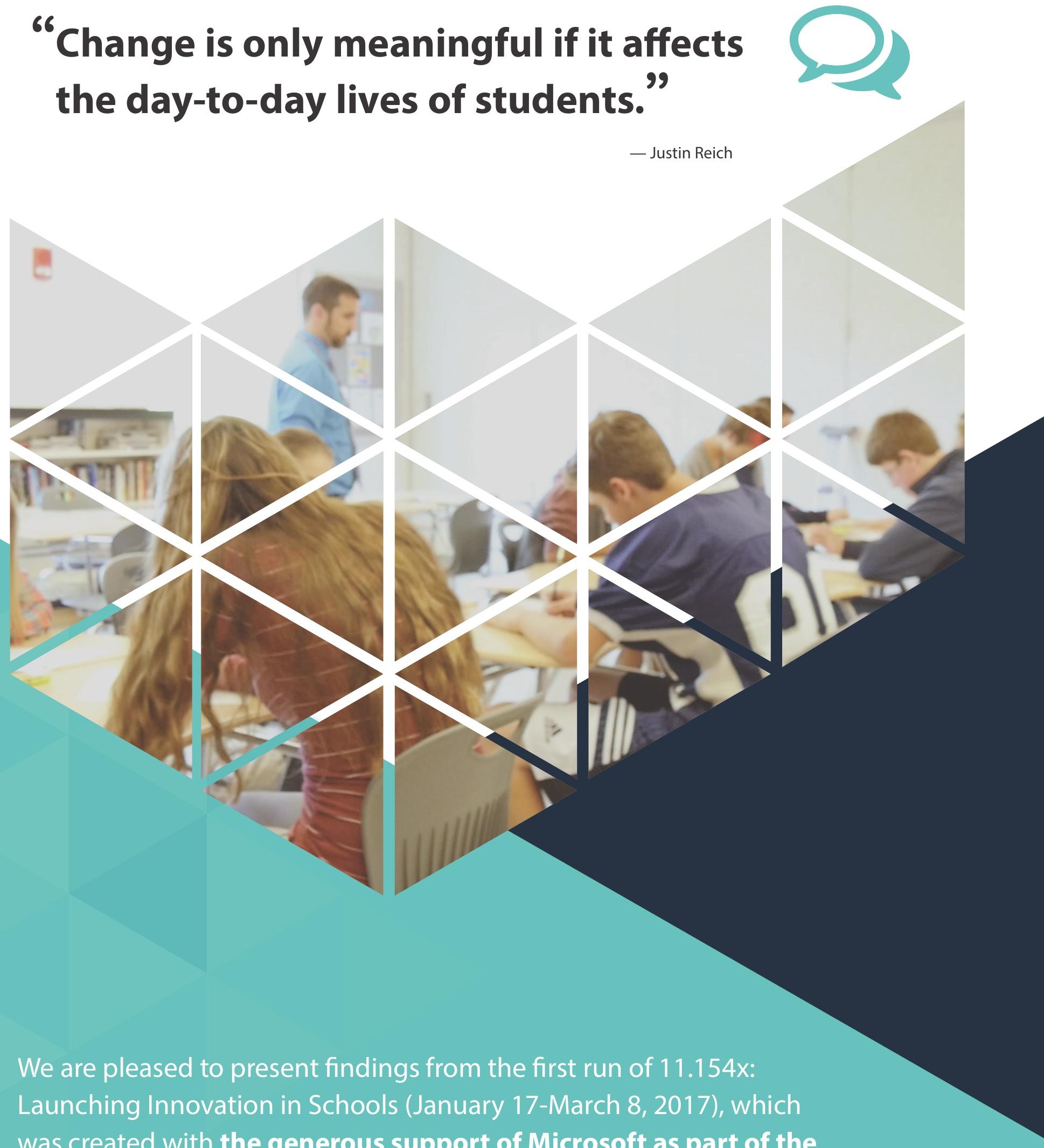
was created with the generous support of Microsoft as part of the Microsoft in Education Series on edX. On the following pages, we provide an overview of the course content, consider the impact of the course, and share insights into the learner experience. 


\section{CONTENTS}

\begin{tabular}{|c|c|}
\hline Executive Summary & 04 \\
\hline Course Overview & 06 \\
\hline By the Numbers & 07 \\
\hline Course Elements & 08 \\
\hline Course Units & 09 \\
\hline Designing for Impact & 10 \\
\hline Measuring Impact & 12 \\
\hline Transforming Learning with Technology & 14 \\
\hline Student Work & 15 \\
\hline Reflection \& Recommendations & 17 \\
\hline Going Forward & 17 \\
\hline Acknowledgements & 18 \\
\hline
\end{tabular}

The Launching Innovation in Schools review was written, edited, and produced by the Launching Innovation in Schools course team: Huttner-Loan, E., Napier, A., Beazley, G., Grubb, R., Reich, J.

This review's content is made available under a Creative Commons CC-BY 4.0 license. Please share widely.

\section{cc creative}

Graphics, images, and template are copyright. No part may be reproduced without written permission.

Source URL: https://tsl.mit.edu/wp-content/uploads/2017/05/LliS_Review_2017.pdf 
11.154x Launching Innovation in Schools Review

\section{EXECUTIVE SUMMARY}

All around the world, school systems are working towards more ambitious teaching and learning in classrooms-moving away from passive lecture, worksheets, and recitation and towards innovations in active, student-centered, technology-mediated learning. Better student learning depends on better teacher learning; school systems need to dramatically increase the quantity and quality of learning opportunities for educators within the system. Online and blended courses and experiences will play a crucial role in making this dramatic increase possible. The Microsoft in Education MOOCs represent an important experiment in using online resources to create new learning opportunities for school leaders looking to take the helm of transformational change in schools.

Created by Justin Reich, Peter Senge, and a team of instructional designers from the MIT Teaching Systems Lab, Launching Innovation in Schools prepares leaders at all levelsteacher-leaders, principals, superintendents, and public officials-for the challenging and rewarding work of innovation. Innovation takes many forms in different cultures and schools, so rather than focusing on any particular instructional approach, Launching Innovation in Schools helps leaders develop the conditions that make any kind of innovation possible. The course helps educators to create healthy soils for innovation in schools and then to think carefully about what to cultivate there. Through expert instruction from Reich and Senge, case studies from seven innovative schools and educational stakeholders, online peer interaction, and activities that get learners back in their schools to make change right away, participants develop a new perspective on leadership through example, practice, and discussion with peers.

The central design challenge of Launching Innovation in Schools is that MOOCs are primarily individual, asynchronous, and online, while school leadership is collaborative, real-time, and situated in specific contexts. For our design team, it's not enough if participants come to Launching Innovation in Schools, watch videos alone at night, and nod along while feeling inspired. We defined success as participants' taking their insights directly back into their communities to start processes of leading change in a single department, an entire school, or across a whole district or system.

Our strategy for tackling the design challenge in Launching Innovation in Schools was to develop new learning techniques that transferred learning in the online setting to action in real contexts. These techniques included anchoring leadership principles in specific practices, encouraging the formation of collaborative learning circles, providing a facilitator's guide for learning circles to use, creating takeout packages that walk leaders through new practices, modeling the process of change in compelling case studies of schools, and offering calls to action that get participants putting their new learning to work right away in their schools. Throughout our design process, we reminded ourselves that the learning that truly mattered was that which transformed participant behavior and changed conditions in their schools.

Measuring the impact of this particular kind of learning is more challenging than tallying correct multiple choice questions or counting the number of discussion posts. We need to 
gather evidence about how over 7,000 educators in 160 countries are implementing ideas from the course in their local context. Our early investigations of surveys and content analysis of student work are very encouraging. The core ideas of the course-encouraging a bias to action, embracing innovation through iteration, building collaborative teams by engaging people around their interests-are reflected throughout student's observations about their learning in student assignments and discussions:

"I used to think that I had to have everything figured out before I start a new initiative, but now I think that it's important to start and iterate to innovate."

"I used to think that leadership was top down but it's clearly not; it's about having team members that share a common vision and values. Also enabling them to have the confidence, opportunity and room to take their own risks, make and learn from their own mistakes and to grow themselves as teachers."

"A group of colleagues from my school all took this course at the same time. While each person followed the course in her/his own way, it has provided us with fodder for productive, generative discussions as well as a group to act as a sounding board for any of our ideas, goals, etc."

"I have an opportunity to launch innovation in my school, probably as a solo effort at first, but I'm already working with a few teachers who are excited about redefining their teaching and collaborating on ways we can improve student learning. I will have to focus on what I can control, but I have collected all of the course materials, and have already started using them in my teaching, as well as sharing them with my colleagues."

As we read these kinds of comments, look at participant work describing their interventions in schools, and continue the process of participant interviews and surveys, it's clear that Launching Innovation in Schools made a substantial impact in the lives of educators around the globe.

The first public run of Launching Innovation in Schools was only the beginning. We plan to revise the course based on participant feedback and run it again in the 2017-2018 and 2018-2019 schools years. We also have proposals to create custom modifications of the course that we will run with particular populations through partnerships with professional development organizations, graduate schools of education, or other entities that can support and scale blended learning, such as the Ministry of Education in Kuwait. We look forward to continuing our work with Microsoft, exploring how our existing courses can be retooled, and how we can develop more courses to advance our shared goals of preparing educators for a more ambitious future of teaching and learning. 


\section{COURSE OVERVIEW}

We invited learners to complete cycles of study, experimentation, and reflection to gain the confidence and skills to lead instructional improvement efforts in their schools. Based on the work of Justin Reich and Peter Senge, Launching Innovation in Schools focused on visioning and capacity-building, with an emphasis on building partnerships with stakeholders at multiple levels.

\section{OBJECTIVES}

\section{LEARNERS WILL:}

- Develop a vision and strategy for change that takes into account change leadership frameworks, local context, and the perspectives of major stakeholders in the educational environment.

- Begin taking steps in their school or learning environment towards launching an instructional improvement initiative.

- Connect, collaborate, and learn with colleagues and peers, both within the course and in their school or organization.

- Understand that different types of school leaders-from teachers to superintendents - have different roles for launching change, but the change that matters most is the innovation that directly changes how students learn in classrooms.

- Develop confidence that they have the ability to adopt and apply new leadership practices and act as change agents.

- Explore how technology can transform learning for adults and students. 


\section{BY THE NUMBERS}

\section{INITIAL COURSE RUN (JANUARY 17-MARCH 8, 2017)}

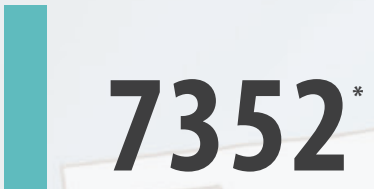

ENROLLMENT

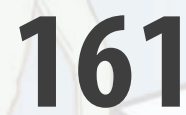

TOTAL COUNTRIES

Learners came from around world. Top countries were US, India, and Brazil.

\section{$76 \%$}

LEARNERS CURRENTLY

EMPLOYED AS AN

INSTRUCTOR/TEACHER
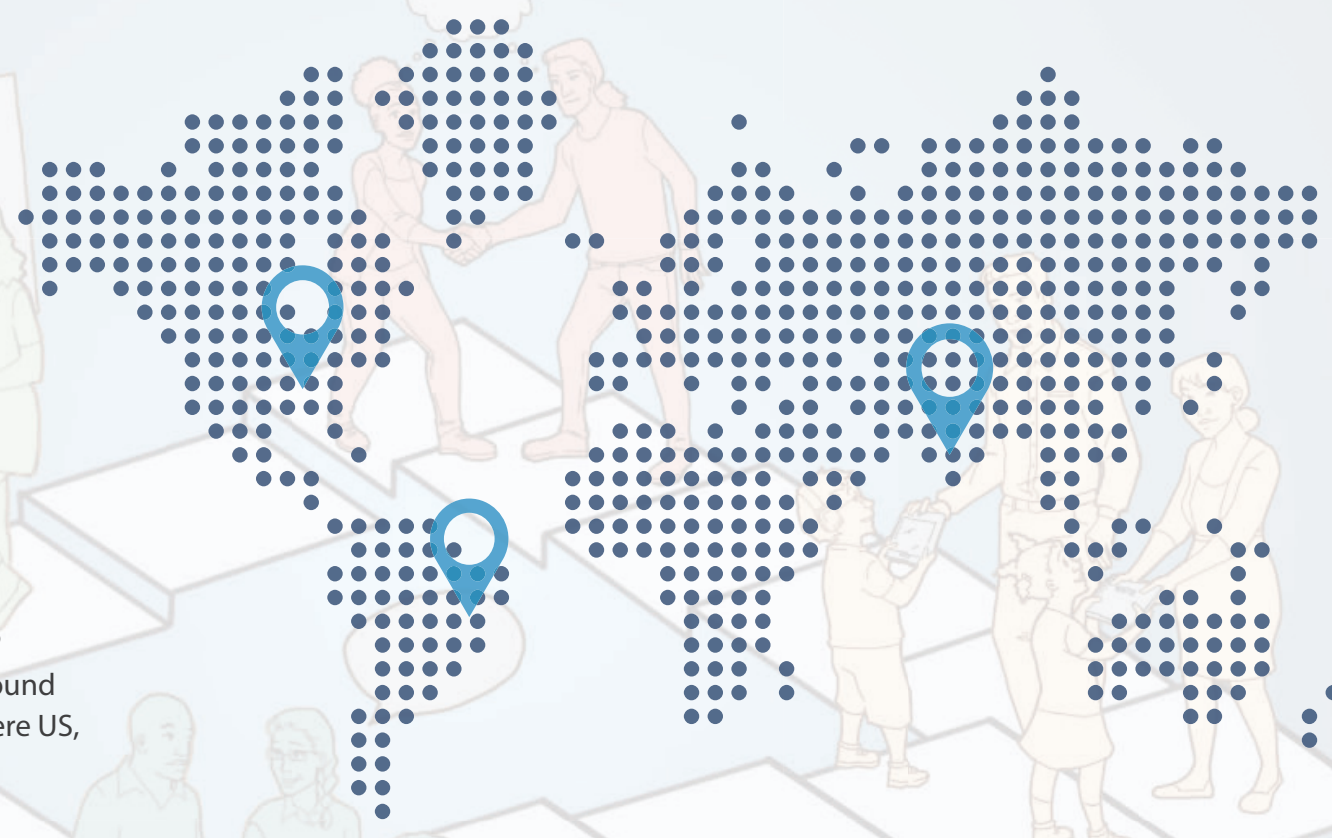

누을 (0) (1)

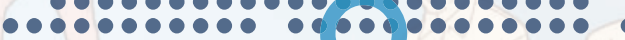
•? ๑ $\bullet \bullet \bullet \bullet$ (0) 论 1000000 10.0000

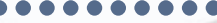
0 $\bullet \bullet \bullet \bullet \bullet$ 웅ำ 100 $0 ?$ 10

$?$ $\because \bullet$ 누웅 100000 $\bullet \bullet \bullet \bullet$ $1 ?$
$60 \%$

LEARNERS WHO HAD RECEIVED AN ADVANCED DEGREE

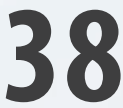

MEDIAN AGE OF LEARNERS

Participants submitted assignments and interacted with other learners in our specially designed discussion forums, which are separate from the edX platform.

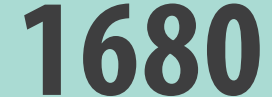

ACTIVE MEMBERS

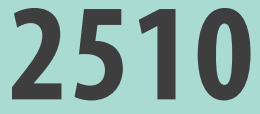

TOTAL TOPICS

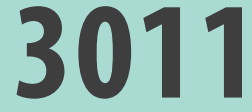

TOTAL REPLIES 


\section{COURSE ELEMENTS}

In every design decision, our central goal was to introduce participants to frameworks for change leadership through a set of practices that they could implement in their own settings.

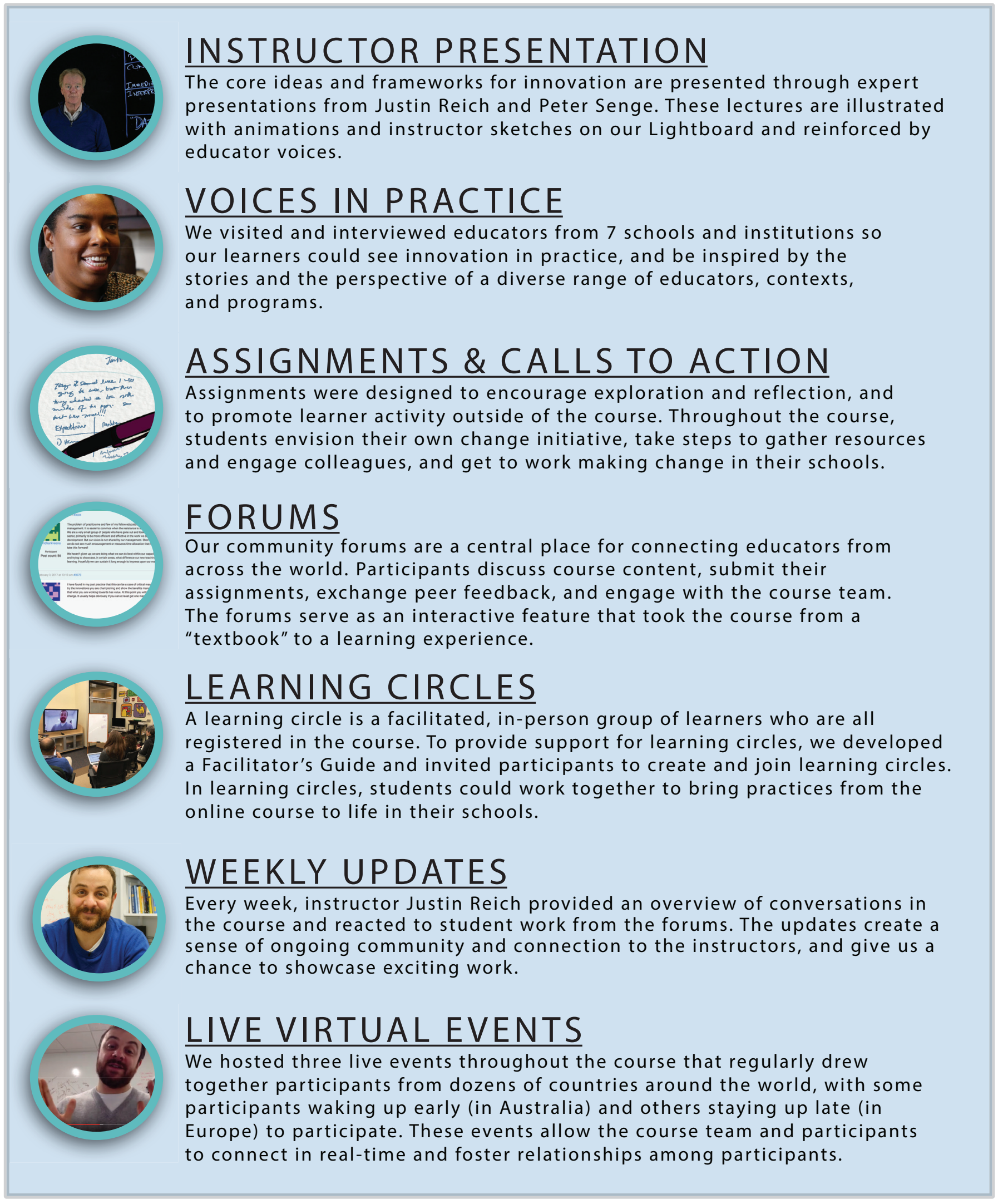




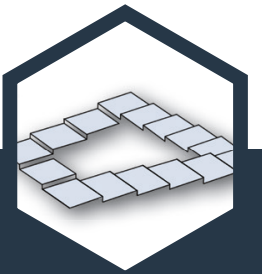

UNIT 1:

\section{Launching Innovation} in Schools

This course begins by introducing the Cycle of Launching Innovation, a four-phase framework for leading change initiatives. Our instructors introduce key leadership tools, and learners see what the Cycle of Launching Innovation looks like in a real school district.

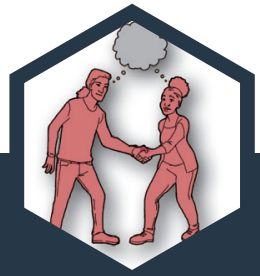

UNIT 2:

\section{Bringing People Together} Around Ideas They Care About

This unit explores how to gain the support and investment needed from others to enact change by tapping into what the community cares about. Learners hear directly from educators who have been effective in engaging with multiple stakeholders.

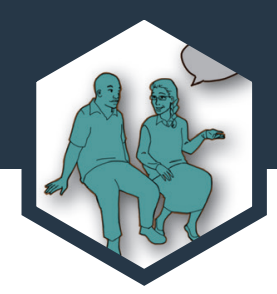

UNIT 4: Working Together Through Ups \& Downs

This unit provides tools for understanding how to work through difficulties and for promoting productive team conversations. Learners reflect on challenges they face and are facing when working with others. Educators and education advocates reflect on the importance of communication and collaboration and the fear that often accompanies change.

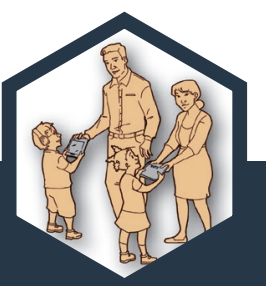

UNIT 3:

\section{Refining a Vision} and Getting to Work

Learners discover how necessary it is that a school or school system have a coherent vision. Using the Cycle of Experiment and Experience, a framework for understanding change in schools, teachers can get to work by experimenting in their classrooms, and administrators can get to work by facilitating teacher experimentation. Learners visit two schools where educators have worked collaboratively to define and shift their visions.

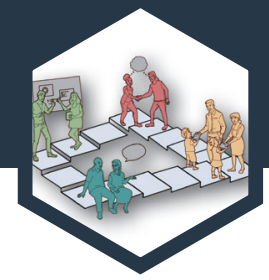

UNIT 6:

\section{UNIT 5:}

\section{Measuring}

\section{Progress and Adjusting}

Our instructors explain why

it is important to measure

progress for an initiative and gives suggestions

for how to do it. Learners hear from educators about assessing pilots in schools and collecting and analyzing data to improve instruction.

\section{Sustaining Innovation in Schools}

Learners consider the importance of continual reflection to sustain innovation. Learners hear from a school featured in Units 1 and 4 about lessons learned and future plans. Our instructors discuss the role of a leader and looking at schools as learning organizations. 


\section{DESIGNING FOR IMPACT}

The primary goal of our course is for participants to take what they have learned about change leadership and put it directly to work in schools. Instead of the usual MOOC practice of studying individually, asynchronously, and online, we encourage our participants to work in collaborative, real-time, face-to-face settings through the following design strategies.

\section{LEARNING CIRCLES}

ENCOURAGING STUDENTS TO TAKE THE COURSE TOGETHER

Even before the course officially launched, we encouraged registrants to join with their colleagues and carve out some time each week to work together, discuss and reflect. At times, these learning circles naturally transitioned into teams leading change.

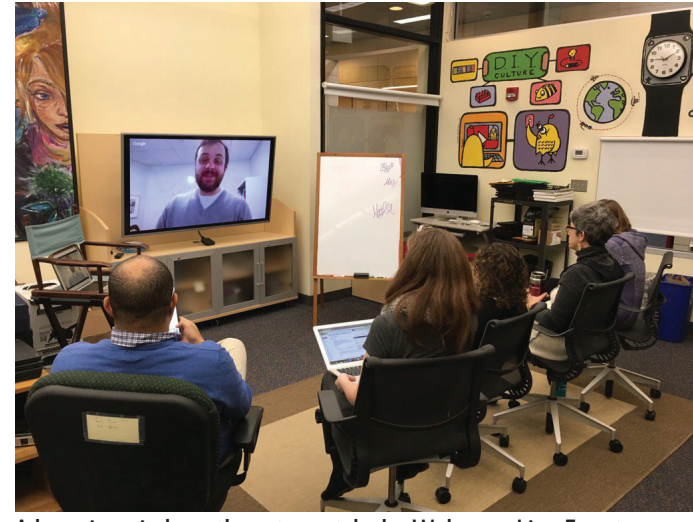

A learning circle gathers to watch the Welcome Live Event. Image Credit: Megan Haddadi, Head of Technology, Park School

\section{FACILITATOR'S GUIDE}

\section{SCAFFOLDING COLLABORATION}

We produced a 30-page guide for facilitators of learning circles that offered video discussion questions, group exercises, and other suggestions for how to learn as a group alongside the online course.

\section{TEACHING THEORY THROUGH PRACTICE}

The course introduced each key leadership theory or framework through concrete practices that school leaders can do with their colleagues. For example, when we described the importance of soliciting stakeholder feedback on vision, we showed how to do that through an activity called Four Corners. When we emphasized the importance of reflecting on collaborative conversation, we showed how the Left-Hand Column Case can help people debug tough conversations.

\section{TAKEOUT PACKAGES}

\section{SUPPORTING PRACTICES}

To help participants go from engaging in online practices to leading them in-person with colleagues, we provided Takeout Packages that function as scripts for leading practices like the Rightboro or Evaluation Scenarios. These scripts give new leaders the confidence to try new practices with their colleagues. 


\section{CASE STUDIES}

\section{SEEING CHANGE IN ACTION}

We visited a diverse set of public, private, and charter schools where outstanding educators illustrate the hard work of making change happen. These case studies helped participants see how innovative change looks in real settings.
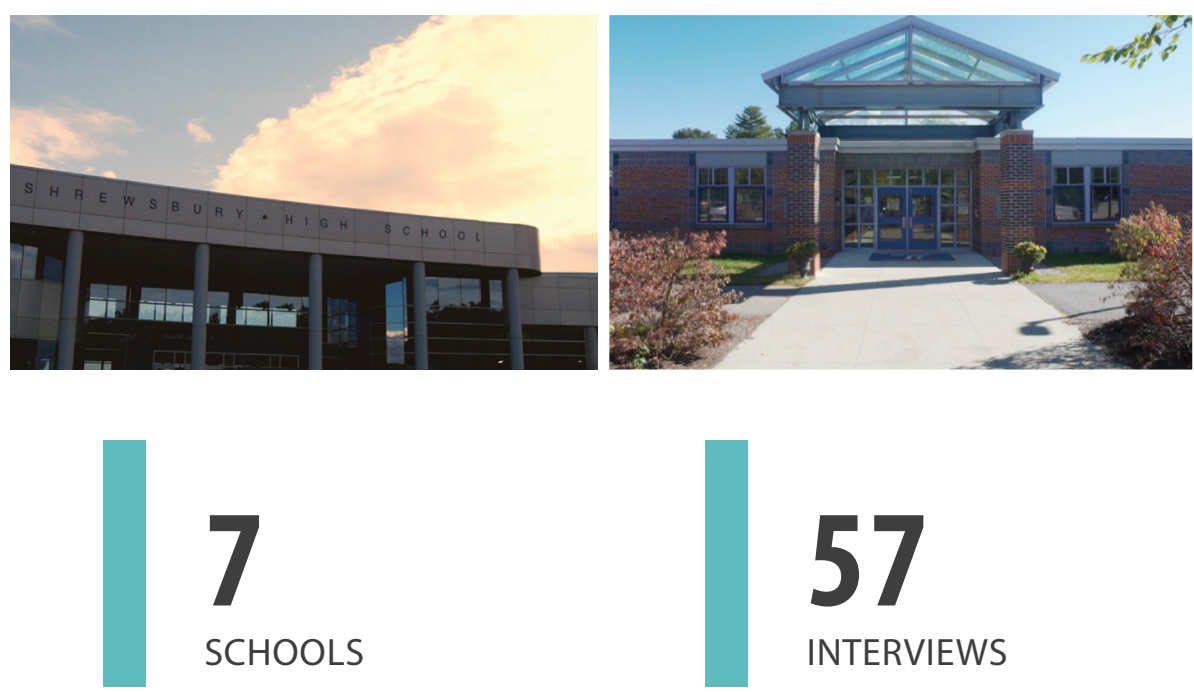

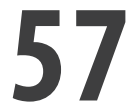

INTERVIEWS
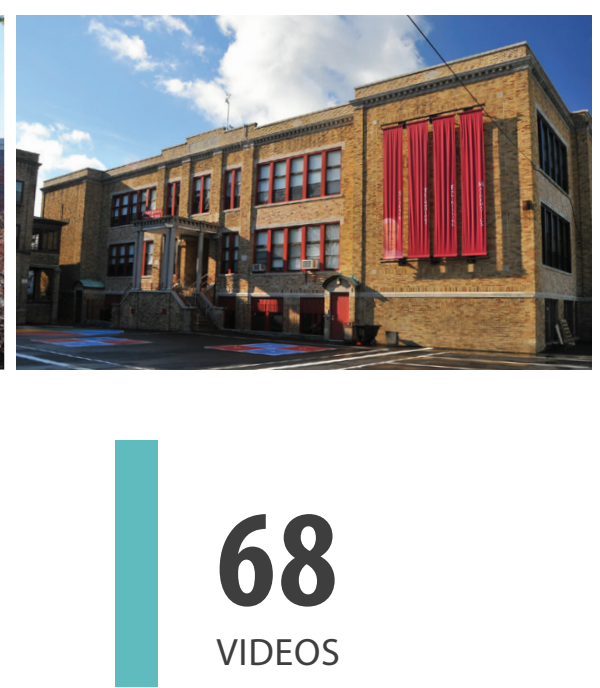

68

VIDEOS

\section{GETTING TO WORK}

\section{ASSIGNMENTS AND CALLSTO ACTION}

The course emphasized a "bias to action," the belief that learning and growth happens through action and reflection. Participants learned theory, saw it in action through case studies, and then got to work themselves through assignments. Each assignment is accompanied by a Call to Action video, which helped participants see how the assignment can be part of a change process in their schools and organizations.

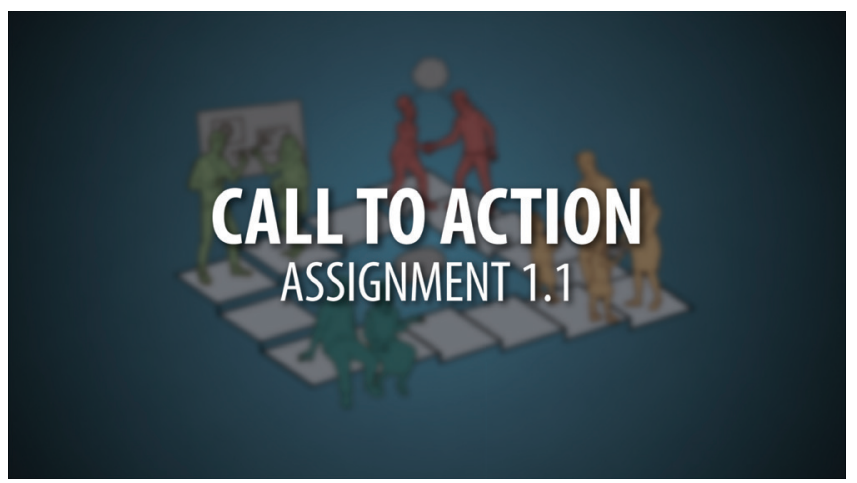

\section{BUILDING FOR EDUCATORS' BUSY LIVES}

Our courses are designed to fit into our participants' busy schedules. We tried to keep course content at 1-2 hours per week to fit within a teacher's prep period or a weekend afternoon. We also designed the course knowing that many students won't complete the course. For instance, our first unit summarizes the key ideas from the entire course, rather than providing just the first content area, so that when people leave the course early, they leave having been introduced to the key concepts. 


\section{MEASURING IMPACT}

Given the ambition of our goals to help educators make real change in their schools, measuring impact is both incredibly important and challenging. Our courseware analytics gives us some sense of participation: over 7,000 registrants from 160 countries, over 3,000 forums posts, and over 19,000 video views. Hundreds of people around the world were actively engaged in the course, and those who participated in surveys reported high levels of satisfaction:

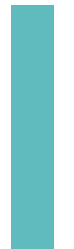

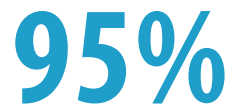

RESPONDENTS WOULD RECOMMEND COURSE TO ANOTHER STUDENT
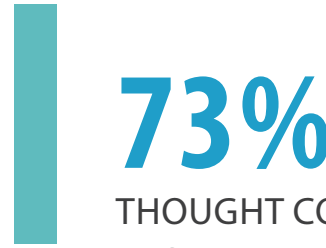

THOUGHT COURSE

EXCEEDED

EXPECTATIONS

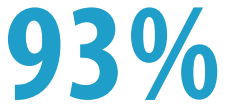

TEACHERS AGREED THEY WOULD USE MATERIAL AND/OR IDEAS FROM THIS COURSE

Aside from analysis of survey data, we also see evidence of impact from student work and reflection. Participants show their understanding and application of the core ideas of the course in observations about their own learning and discussions with peers.

"This course has left me with two major take-aways. The first is the reminder that "leadership" is an action, not a title. This prods me to focus my energies on how I can effect positive change by leading with my actions and interactions regardless of my title or position within the school and by encouraging others to do the same. The second is the encouragement to use systematic, structured activities to reflect, plan, and assess."
" Today was a good day and I'm feeling really positive! I attended a secondary department meeting to share information and gather opinions. I worked with three staff members to ensure our technology was meeting their teaching and learning needs. I co-planned a year 4 geography unit that integrates tech in a creativeway and theyear 4 teacher was excited about co-teaching the lessons. We discussed the fact we had attempted something similar last year and were pleased to be refining the lessons. We discussed the cycle of experiment and experience."
"I am a STEM teacher at a small, private K-8 school of varied level learners from diverse backgrounds. I wanted to create a program to teach them code that goes beyond the hour of code, that is more engaging and that would allow them to move to the next level. So far so good! I designed it and began it this last semester and have had enough success that my principal is happy and wants it to continue next year! Yay!"

"The course definitely developed my self esteem related with initiating something within school. Knowing that as a teacher part of my job is to be a leader, made me motivated to fulfill that role." 
Given that our course is intentionally designed to support learners participating to different degrees, course completion should be considered carefully. Like most MOOCs, the numbers of participants who completed the course was small in percentage terms: there were 125 students who earned certificates in the course and 81 students who completed the final project.

Each learner comes to the course with his or her own set of goals, resources, circumstances, and commitments. Not every learner intends or desires to watch all video content or complete every assignment. From surveys, interviews, and analysis of course content, we know that partial participation is highly valued.

66

The learning circle we formed to take the course has been able to establish a real purpose, and the process we learned from the course gave us clear direction on how to proceed. Although none of us completed the course, it gave us the impetus to identify an innovation to improve learning at our institution (delay the start of lessons to 09:40) and strive to work through the launching innovation steps. We created an asset map, and have met with a number of the key stakeholders. We are now getting input from our teaching colleagues, and have also surveyed the students. The next step is to work with our administration to get their support to take the innovation on board. " $-11.154 x$ Learner

As we continue to explore the impact of Launching Innovation in Schools through surveys, interviews, and other regular communications with our learners, we find more and more indications that Launching Innovation in Schools has been a catalyst for teachers and school leaders to begin leading ambitious change initiatives around the world.

We invited regional participants to a leadership, innovation and design Edcamp on August 9, 2017. We'd be delighted to have anyone from Microsoft join us! We see this Edcamp as an opportunity to continue engaging with our learners and to learn more about the different initiatives sparked and accelerated by Launching Innovation in Schools. 


\section{TRANSFORMING LEARNING WITH TECHNOLGY}

One objective for this course was to have our learners explore how technology can transform learning for adults and students. Below we share examples of how learners used the concepts and tools of our course to launch technology initiatives in their schools.

Problem of Practice: abundance of apps and lack of technology benchmarks for each grade leve

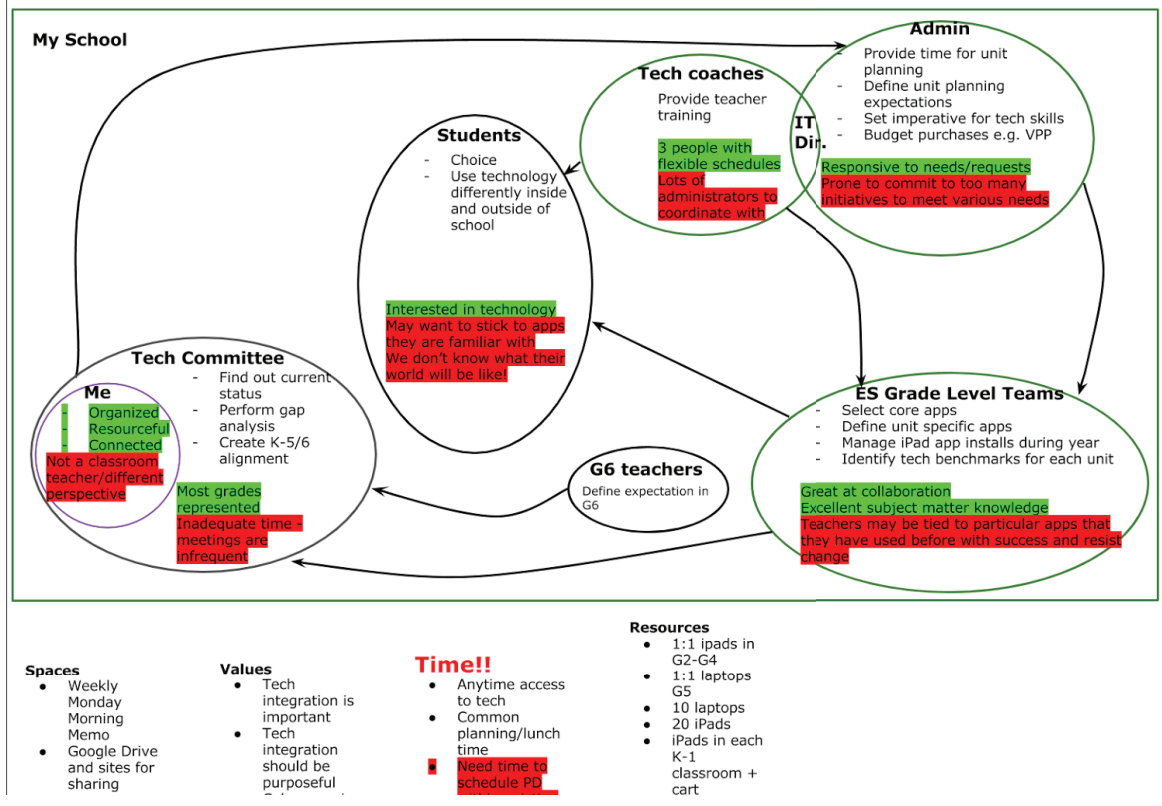

"Our district too is moving forward with OneNote and the Office 365 platform. Microsoft has made some amazing advancements with Classroom - Data Sync - MIE for teachers. I agree with you $110 \%$ and love the ability for face to face collaboration is a must but now can be achieved with Sykpe.
"With a new competences-based curriculum in the pipe-line and the provision of 1:1 digital devices for every student it is a good time for our school to reflect our teaching practices and develop new forms of learning scenarios for ours students in all classes."

"I used to think that

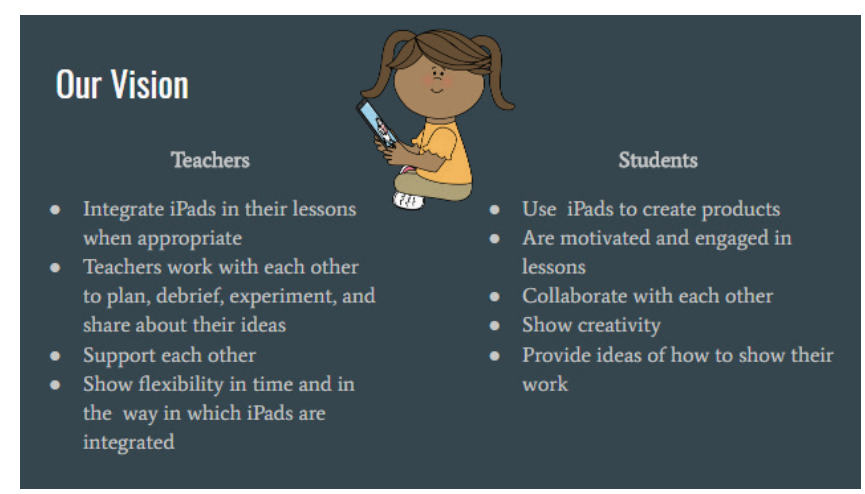
devices would be the saviour of teaching in the classroom, and that devices mattered. I now think that it's not the power of the device, it's the power of the teacher and what they can do."
" $O$ ne of the readings in Unit 3 jumped out at me (Daccord, Tom and Justin Reich. 2015. "How to Transform Teaching with Tablets." Educational Leadership 72 (8): points I took from this reading (amongst other great info) was the fact that we are probably a school that has invested in technology and not had a vision for how this is going to improve our teaching. It is only now, 5 years into the intro of technology and about 3 years into a BYOD program in the high school that we have the time and human resources to begin to build our vision and change the way we teach with technology." 


\section{STUDENT WORK}

\section{Our assignments were created to help learners to reflect and act. We encouraged our participants to apply what they learned from the course in their own settings.}

\section{ASSIGNMENT 1.1}

\section{POWERFUL LEARNING ENVIRONMENT}

Learners begin to shape what good teaching and learning looks like for them by describing their vision of a powerful learning environment.

\section{ASSIGNMENT 1.2 PROBLEM OF PRACTICE}

Though our learners came from all over the world, the challenges they face in schools and classrooms were very similar. We asked participants to pick a problem of practice to work on throughout the course. A problem of practice is a challenge in the learning environment that impedes student learning. Our students chose to work on a wide variety of topics including:

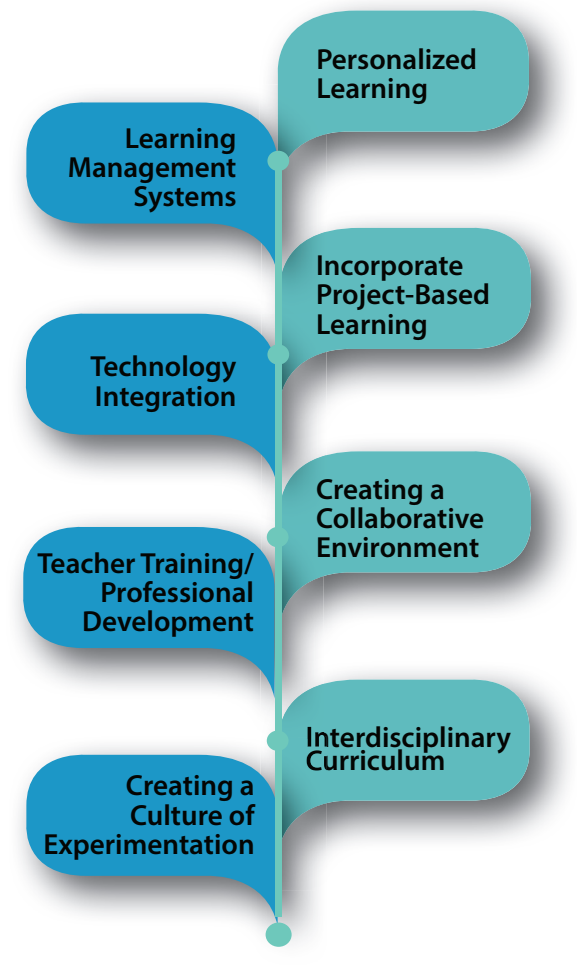

\section{ASSIGNMENT 2}

\section{ASSET MAP AND REFLECTION}

To identify useful resources to help tackle their problem of practice, participants create an asset

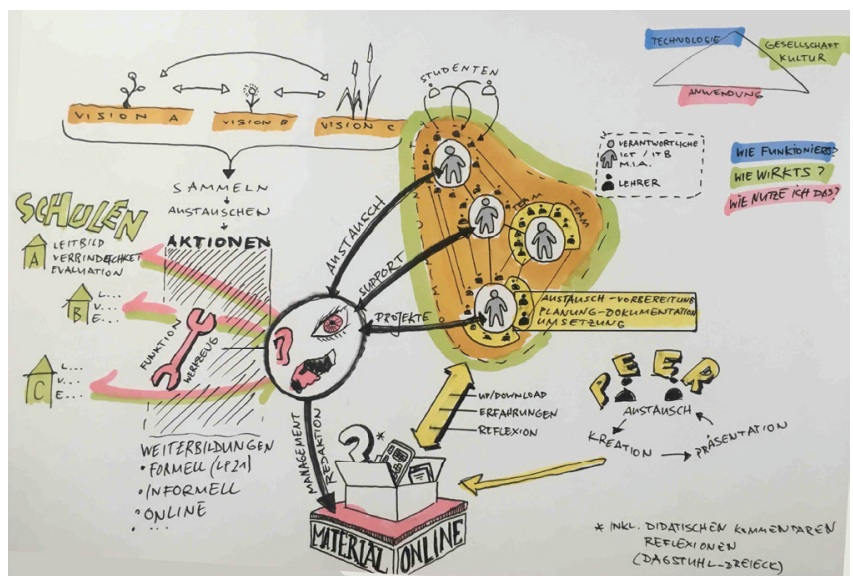

This asset map emphasizes the important role of students as well as a variety of ways to collaborate.

"My support network and 'assets' are far greater than I had anticipated. With time, respect, encouragement and motivation people really will gather together and work towards creating and achieving a shared vision." 


\section{INITIAL ACTION PLAN PART 1 WHAT DOES AWESOME LOOK LIKE?}

This assignment guided learners toward reflecting on their personal vision of what would make a positive outcome for fixing their problem of practice.

\section{INITIAL ACTION PLAN PART 2 FIRST CONCRETE STEPS}

This course emphasizes a bias to action. With the Initial Action Plan assignment we challenged participants to not only create a plan for action, but to take action.

This particular learner implemented the first steps of his Initial Action Plan during the course. He posted photos of introducing his problem of practice solution to his colleagues.

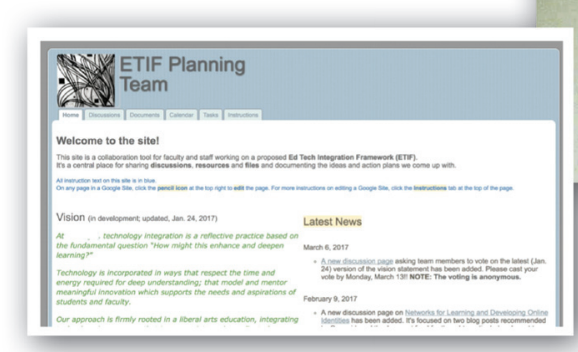

"Very soon, ... we will have some discussions forums with school leaders in order to assess the implementation of a project in Portuguese schools and discuss with them ways of trying and implementing project-based learning activities related to entrepreneurial challenges in the curriculum."

edX Launching Innovation in Schods.

Initial Action Plan Part 1.

what does Awesome nok like

POP: Developing creative design skills for future suceers.
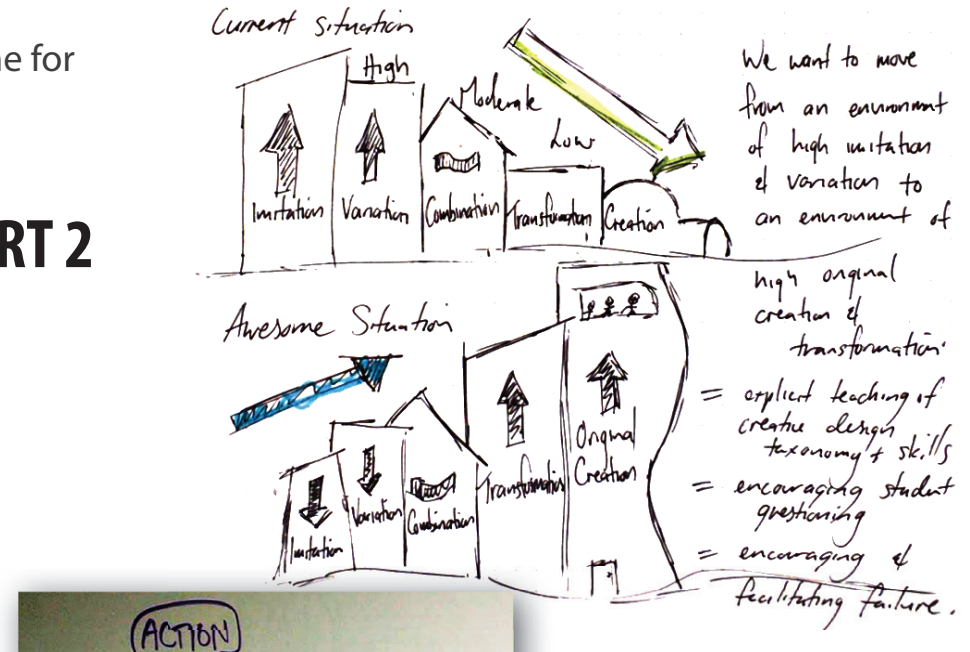

2wasks: Online collabriation (INMEDIFTE ACTINS) Space presenting problem of prectice \&

NPUT: Ask mentor for ideas HEQP RROM OAFERSS) Re. potential working group
members Experimeat: Get one teachar to (PRoOF of "I west prectice" methodology EXEMPLAR) for piloting ine use of

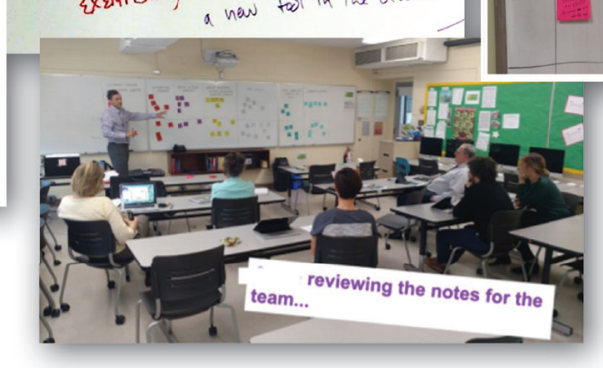

"I managed to organize a day session with 40 physics teachers from secondary schools in my district and they really appreciate it. Now we are working on a long term project in launching innovations in classrooms: a physics approach."

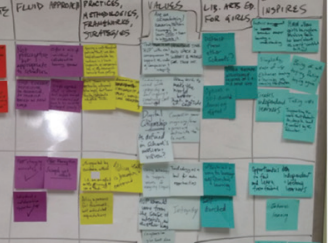

" The concepts and understandings gained will directly inform my approaches to leading a group of faculty to create and implement a technology integration framework at our K-12 school. It may also inform the way our school approaches innovation in general, since I work closely with some members of the senior leadership team."

\section{INITIAL ACTION PLAN PART 3 ASSESSMENT PLAN}

If anything is worth doing, it's worth figuring out if you've done it right. For the last part of the Initial Action Plan, participants created an assessment plan that described how they will measure the progress for their initiative. 


\section{REFLECTION \& RECOMMENDATIONS}

The first run of Launching Innovation in Schools was a great success, and we have exciting plans for how to continue to serve educators with these materials. We have a few recommendations to make for future runs.

- Diversity of voices. While we were excited to be able to feature many different voices from different types of schools, the course team values diversity and would appreciate the opportunity to interview educational leaders, and others, out of the New England area. We believe this would expand the appeal of the course even further and also allow learners to gain valuable perspective.

- Adjusting Pacing. We designed the course to take 1-2 hours per week, but many participants reported spending four or more hours per week. In subsequent runs, we plan to streamline the content to emphasize the most valuable elements, consider some content restructuring, as well as adjusting the pacing to allow learners to have more time for viewing content and completing assignment work.

- Support for collaboration. Recognizing that change in schools can't happen in isolation, we encouraged learners to find colleagues to also take the course. However, many learners were in circumstances that prevented them from taking the course with colleagues. In our next run of the course, we would like to provide a support guide to encourage and help learners to leverage our forums' virtual groups feature. For those learners who are able to facilitate learning circles, we would like to provide additional guidance and support.

- Partnering for Delivery and Impact. We're exploring several different potential partnerships to identify specific cohorts of educators to participate in the program. The XQ Super Schools are interested in taking advantage of these resources, and we're working with them to figure out how to serve the 40,000 educators who participated in the contest. We're also pursuing work with the Ministry of Education of Kuwait to create opportunities for 2,000 school leaders in that country to participate. We think there might be other exciting opportunities to partner with Microsoft networks to offer a similar high-touch, high-value program.

\section{GOING FORWARD}

The future of Launching Innovation in Schools and the Microsoft in Education MOOC series is bright. Between Launching Innovation in Schools and Design Thinking for Leading and Learning, we have already engaged thousands of educators around the world and helped prepare them for the challenges of the next decade of educational reform. We are developing new partnerships with additional organizations. We are enormously grateful to Microsoft for supporting this work, and we'd be excited to engage in further conversations about how we can partner around developing more courses or finding new ways to deploy these existing materials in ways that advance powerful uses of technology in education. 


\section{ACKNOWLEDGEMENTS}

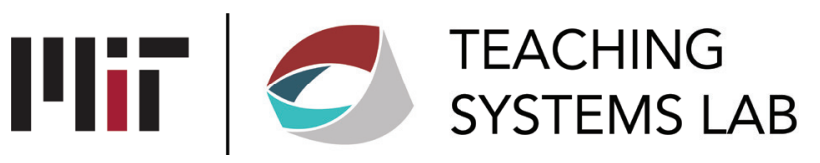

This course could not have happened without the collaborative efforts of staff across MIT, edX, and our freelancers.

We would like to thank the following people who contributed to the creation, development, delivery and marketing of this course.

Course Instructors:

Justin Reich

Peter Senge

Course Staff:

Elizabeth Huttner-Loan

Alyssa Napier

Vladena Baetge Jahn

Garrett Beazley

Rachel Grubb

Engineer for Forums:

Kevin Robinson

Paul Medlock-Walton

\section{Key Team Members at MITx:}

Brad Kay.Goodman

Colleen Cressman

Shelly Upton

\section{Special thanks to FreshCognate}

for additional video production

work and assistance:

Aimee Corrigan

Doug Pietrzak

Denez McAdoo

Daymian Mejia

And Patrick Yurick, for help

in the early phases of course

development. 